\title{
Health Self Efficacy and African American Male Inmates Prior Substance Use Treatment History: Implications for STI Risk Reduction
}

Stephens S*, Holmes T-K and Allen A

Department of Psychology, Clark Atlanta University, Georgia, USA

*Corresponding author: Torrance Stephens, Department of Psychology, Clark Atlanta University, Georgia, USA

Received: February 20, 2017; Accepted: March 15, 2017; Published: March 21, 2017

\begin{abstract}
Objective: This study examines health self-efficacy in a sample of African American adult male inmates in Georgia as a function of past self-reported history of having received treatment for a drug problem prior incarceration.

Methods: Data were collected at baseline by trained interviewers inside selected correctional facilities. There were 126 African American male respondents included in our investigation. The mean age for offenders who selfreported prior drug abuse treatment was 27.62 years $(S D=3.37)$. Chi Square test for consistency was employed to investigate the significance between the observed frequencies for all dichotomous the distributions and significance tests were conducted using univariate logistic regressions to examine the independent associations of lifetime self-reported past drug abuse treatment history and dichotomized Health Self-efficacy correlates prior to incarceration.

Results: Analysis revealed that inmates with a history of prior substance use treatment reported higher levels of health self-efficacy with respect to doing things in moderation $\left[\mathrm{X}^{2}(1)=3.51, \mathrm{p}<.05\right]$, avoiding over working $\left[\mathrm{X}^{2}(1)=\right.$ $3.39, p<.05]$, and limiting the consumption of foods that contained fats and sugars $\left[X^{2}(1)=5.15, p<.02\right]$. Moreover, African American male inmates with a past history of participating and/or receive some form of substance abuse treatment were more than 2.5 times more likely to report being more likely to use health protective information $(\mathrm{OR}=2.46,95 \% \mathrm{Cl}=0.94-6.42)$ and almost two and a half times more likely to indicate they would avoid drinking and partying too much upon release from prison if they had been part of a substance use treatment program prior $(\mathrm{OR}=2.41,95 \% \mathrm{Cl}=1.04-5.87)$.
\end{abstract}

Conclusions: This study has clinical relevance in the development of substance use treatment and patient education materials on STI risk reduction for offender populations. In particular because of since the correctional setting presents an opportunity to access a significant subset of this population and provide ethical, evidence-based interventions.

Keywords: Inmates; Sexually Transmitted Infections (STI); Substance Use; Health Self Efficacy; African Americans

\section{Introduction}

African American men are disproportionately represented in the U.S. correctional system; evince exceptionally high rates of infectious diseases such as HIV/AIDS [1-4] and like many inmate populations, problem behaviors associated with drug and alcohol use [5-12]. According to the US Bureau of Justice Statistics (BJS) in 2013 there were 2,220,300 adults incarcerated in US federal and state prisons, and county jails with 4,751,400 adults in 2013 being on probation or on parole [13]. Of this number, approximately $35 \%$ of jail inmates, and $37 \%$ of prison inmates of the 2.2 million male inmates as of 2014 are African American [14] albeit around $12-13 \%$ of the American population is African-American [15].

Many factors contribute to these disparities but what cannot be ignored is that both recidivism and substance abuse can be reduced considerably through interventions designed specifically for inmate populations that address health efficacious practices and substance use treatment. In particular since in the U.S. substance abuse is a major influence on risk practices associated with the transmission of infectious disease. For example, nearly one quarter of all HIV-positive individuals pass through the correctional system each year, of which a sizable percentage have self-reported substance use problems [16-17]. This makes the study of health behaviors among inmate populations an issue of major significance for public health, given the majority of all inmates are released back into their home communities.

Notwithstanding, as a parameter of inmate populations, African American inmates have been shown to be at even greater risk than the general inmate population, with the rate of among jail populations, African American men being 5 times more likely as white men, and twice as likely as Hispanic/Latino men, to be diagnosed with HIV [18]. Consequently, substance use treatment, when effective, not only reduces problem behaviors that increase incarceration, but also
J Fam Med - Volume 4 Issue 3 - 2017

ISSN : 2380-0658 | www.austinpublishing group.com

Stephens et al. (C) All rights are reserved
Citation: Stephens S, Holmes T-K and Allen A. Health Self Efficacy and African American Male Inmates Prior Substance Use Treatment History: Implications for STI Risk Reduction. J Fam Med. 2017; 4(3): 1114. 
reduces the level of sexual risk taking. Specifically because drug use inclusive of injection drug use, enhance infectious disease risk of inmate populations since harm reduction methods, such as condoms and needle sterilization equipment, is limited and rarely practiced in U.S. correctional facilities [19-21].

\section{Theoretical Framework}

Research on drug use among incarcerated populations is extensive; however, it often fails to examine theoretical issues associated with enhancing behaviors that encourage inmates to seek health treatment for problems such as substance abuse and misuse. One theoretical behavioral construct that has attracted a significant amount of attention in research regarding health self-protective behaviors and practices is self-efficacy [22-31]. The concept of self-efficacy is based on social cognitive theory, which describes the interaction between behavioral, personal, and environmental factors in health and health behaviors [32]. Self-efficacy asserts that individual's confidence in their ability to perform health behaviors influences which behaviors they will engage in [32-35].

Since extreme risk taking associated with excessive substance use places inmate populations are at risk for a multitude of negative health outcomes which involve behavioral, personal, and environmental factors, understanding behavioral constructs such as self-efficacy is relevant if the goal is to improve health outcomes affiliated with substance use practices. This has been documented in the scientific literature as it pertains to self-management interventions designed to improve health by enhancing individual self-efficacy for many chronic health conditions [36-38].

The issue is that among inmate populations, aspects of Bandura's (1977) social cognitive theory has yet to be examined in relation to substance use treatment, but there is some limited research exploring self-efficacy among inmate populations. Loeb and Steffensmeier (2006) examined the relationships between health status and selfefficacy beliefs in a convenience sample survey of 51 older male prisoners with multiple chronic health conditions and found that Inmates with greater self-efficacy in their health self-management abilities were significantly more likely to rate their health as better, and engage in more health-promoting behaviors since incarceration [39]. With these exceptions, most studies that look at self-efficacy among inmate populations with respect to STIs and associated skills including but not limited to condom use [40].

Investigations of efficacy expectancy (the belief that one can successfully execute behaviors needed to produce a desired outcome) with respect to substance use treatment outcomes although wellreceived, has never been examined of an exclusive sample of African American offenders. What has been demonstrated is that self-efficacy is a predictor of treatment outcome in terms of the amount of alcohol or drugs used [41,42] and that higher self-efficacy predicted less cocaine use only after 3 months but not after 6 months [43]. Others have reported that self-efficacy levels were strongly associated with the amount of subsequent alcohol and crack cocaine use and also the amount of participation in continuing substance treatment programs [44].

Given the aforementioned, this study will examine health selfefficacy in a sample of African American adult male inmates in
Georgia as a function of past self-reported history of having received treatment for a drug problem prior incarceration. Our analysis was designed to evaluate the null hypothesis that there would be no differences between male offender's levels of self-efficacy as a function self-reported having received treatment for a drug problem prior incarceration. If differences are evinced, we anticipate that adult male offenders that have sought or received treatment for a drug problem prior incarceration will show higher levels of health selfefficacy. This study is significant because it extends the current body of scientific information regarding health self-efficacy with respect to substance use treatment seeking behaviour specific to data collected from a random sample of African American adult male inmates, a population consider at extreme risk for substance misuse and abuse. The goal is to use this information such to enhance substance abuse treatment protocols in concert with STI risk reduction.

\section{Methods}

This investigation was part of a study designed to implement a health education intervention to soon-to-be-released adult male inmates. Pilot testing of interview materials occurred in a fifth medium security facility not included in the baseline. The university institutional review board approved all study protocols.

Data were collected at baseline (prior to implementing the intervention), at release, and at three, six, and nine months postrelease. However, only baseline data are presented in the current study. Trained interviewers and peer educators collected data inside the correctional facility. After explaining the purpose of the study and obtaining written informed consent, the interviewer reviewed the data collection instrument with each participant. The instrument was written on a fourth grade reading level and, as noted previously, pre-tested prior to actual data collection. Inmates received monetary incentives and personal kits (including materials related to the intervention) when participating in the follow-up interviews.

\section{Participants}

The study target population was soon-to-be released adult male inmates enrolled in a randomized trial of a human immunodeficiency virus/ recidivism prevention program. Eligibility for this study required that inmates be at a point between 60 and 90 days prior to release from the facility and returning to the metropolitan area of a major southeastern city. Participants were recruited from a population of inmates at three medium securities correctional institutions for men located in middle Georgia and a transitional center located in a major southeastern city.

All study participants who had completed a baseline survey at the time and self-described as African American were included in this analysis. The basis of the health education curriculum provided participants with information related to health, infectious disease transmission, substance use behavior, personal health empowerment and community reintegration methods unrelated to sexual risk behaviors.

\section{Measures}

Demographic Variables: Participants were asked to provide descriptive and scale information on several variables using standard response formats. Socio-demographic variables on the data collection instrument included: ethnicity, marital status, educational level, 
Table 1: Demographic profile of study participants based on history of past treatment (missing values not included).

\begin{tabular}{|c|c|c|c|}
\hline \multirow{2}{*}{ Variable } & Prior Treatment \% & No Treatment \% & \multirow{2}{*}{$\mathbf{p}$} \\
\hline & $\mathrm{n}=\mathbf{2 9}$ & $\mathrm{n}=96$ & \\
\hline Highest Grade of School Finished & & & .11 \\
\hline $8^{\text {th }}$ or less & $6.9(2)$ & $3.1(2)$ & \\
\hline Some HS, didn't Finish & $24.1(7)$ & $39.6(38)$ & \\
\hline Graduated HS or GED & $31.7(15)$ & $32.3(31)$ & \\
\hline Vocational, Trade or Tech School & $6.9(2)$ & $1.0(1)$ & \\
\hline Started College, didn't finish & $6.9(2)$ & $19.8(19)$ & \\
\hline Graduated College & $3.4(1)$ & $3.1(3)$ & \\
\hline Finished Post Grad or Professional Degree & $0.0(0)$ & $1.0(1)$ & \\
\hline Household Income Prior Arrest & & & .51 \\
\hline Under $\$ 10,000$ & $31.0(9)$ & $16.5(16)$ & \\
\hline$\$ 10,000-\$ 19,000$ & $20.7(6)$ & $19.6(19)$ & \\
\hline$\$ 20,000-\$ 29,000$ & $17.2(5)$ & $26.8(26)$ & \\
\hline$\$ 30,000-\$ 39,000$ & $10.3(3)$ & $9.3(9)$ & \\
\hline$\$ 40,000-\$ 49,000$ & $6.9(2)$ & $4.1(4)$ & \\
\hline$\$ 50,000-\$ 59,000$ & $3.4(1)$ & $7.2(7)$ & \\
\hline$\$ 60,000-\$ 69,000$ & $6.9(2)$ & $4.1(4)$ & \\
\hline$\$ 70,000$ Plus & $3.4(1)$ & $12.4(12)$ & \\
\hline
\end{tabular}

income prior to incarceration, and incarceration history. Several individual items represented incarceration status. Length of incarceration was an open ended item that asked participants to write the total years served during their recent incarceration. Prior or first time incarceration was measured with a dichotomous response item worded: "Was this your first time being incarcerated?" (Table 1).

Health self efficacy: This construct was measured using twentysix items in the survey instrument measured on scale from 0 to 100 ( 0 $=$ not at all confident to $100=$ very confident $)$. All items were prefaced with "How confident that after being released from prison." Examples include eat sensibly, not smoke cigarettes, do things in moderation and see a doctor for a regular check-up. Participants with missing data were not included in the analysis. Reliability analysis resulted in Cronbach's alpha $=.859$ for the twenty six sample scale for study participants.

\section{Analysis}

Demographic variables were examined using measures of central tendency and dispersion. Chi Square test for consistency was employed to investigate the significance between the observed frequencies for all dichotomous the distributions. Next, significance tests were conducted using univariate logistic regressions to examine the independent associations of lifetime self-reported past drug abuse treatment historyand dichotomized Health Self-efficacy correlates prior to incarceration. Adjusted odds ratios (ORs) with 95\% confidence intervals (CIs) are presented. Univariate regression analysis was selected because of the assumption of normality and because the least squares regression curve would minimize the sum of squared differences between the estimated and the actual y values for given $\mathrm{x}$ values $[45,46]$. Therefore, the sum of squares and partial derivatives of each parameter estimated in each equation are defined and equated to zero (Table 2).

\section{Results}

There were 126 African American male respondents included in our investigation. The mean age for offenders who self-reported prior drug abuse treatment was 27.62 years $(S D=3.37)$. Study respondents without a past history of substance abuse treatment had a mean age of 31.9 years $(\mathrm{SD}=4.77)$. Offenders with past treatment history reported a mean of 3.7 years incarcerated $(S D=2.3)$ with a range of 1 to 10 years compared to 4.65 years $(S D=6.96)$. Offenders who reported having been treated for drug abuse were more likely to have had graduated high school or received their GED (51.7\%) compared to their confederates (32.3\%). In fact the majority of offenders not reporting drug abuse treatment prior incarceration (39.6) reported having attended high school but never finishing. Also, offenders who reported having been treated for drug abuse were more likely to reported making less than $\$ 10,000$ (31.0\%) and between $\$ 10,000$ to $\$ 19,000$ (20.7\%) annually prior incarceration. Offenders not reporting drug abuse treatment prior incarceration reported having earned on average between $\$ 20,000$ and $\$ 29,000$ a year $(26.8 \%)$. In addition, most participants had been arrested prior in both the treatment (75.9) and non-treatment (64.9).

In terms of sexual behavior, study participants reported that their age for first wiling having vaginal sex and oral sex were 13.72 (SD = $2.64)$ and 18.03 years $(\mathrm{SD}=6.88)$ accordingly.

Chi Square analysis revealed that inmates with a history of prior substance use treatment reported higher levels of health self-efficacy with respect to doing things in moderation $\left[\mathrm{X}^{2}(1)=3.51, \mathrm{p}<.05\right]$, avoiding over working $\left[\mathrm{X}^{2}(1)=3.39, \mathrm{p}<.05\right]$, and limiting the consumption of foods that contained fats and sugars $\left[\mathrm{X}^{2}(1)=5.15\right.$, $\mathrm{p}<.02]$. Moreover, offenders with a history of prior substance use treatment had higher health self-efficacy regarding not letting things 
Table 2: Chi square analysis of self-efficacy items and prior treatment in substance abuse/use program, African American male inmates.

\begin{tabular}{|c|c|c|c|}
\hline After being released from prison & $\mathbf{C}^{2}$ & df & $\mathbf{p}$ \\
\hline Eat Sensibly & 0.65 & 1 & 0.47 \\
\hline Get Enough Exercise & 0.65 & 1 & 0.41 \\
\hline Get Enough Sleep & 1.07 & 1 & 0.29 \\
\hline Get Enough Relaxation & 1.14 & 1 & 0.28 \\
\hline Watch Your Weight & 2.48 & 1 & 0.11 \\
\hline Not Smoke Cigarettes & 0.07 & 1 & 0.93 \\
\hline See a Doctor For Regular Check Up & 1.94 & 1 & 0.16 \\
\hline Do things in moderation & 3.51 & 1 & 0.06 \\
\hline Avoid Over Working & 3.39 & 1 & 0.06 \\
\hline Limit Foods containing Fats and Sugars & 5.15 & 1 & 0.02 \\
\hline Not Let Thing Get You Down & 4.34 & 1 & 0.03 \\
\hline Take Weekly Saunas & 0.11 & 1 & 0.73 \\
\hline Prevent Illness by Following suggestions of local pharmacist & 0.24 & 1 & 0.62 \\
\hline Keep Cold Remedies and Aspirin around the House & 0.01 & 1 & 0.97 \\
\hline $\begin{array}{l}\text { Use Health Protective Information provided by a Health } \\
\text { Columnist }\end{array}$ & 0.06 & 1 & 0.93 \\
\hline Avoid getting chilled & 0.45 & 1 & 0.5 \\
\hline Adhere to diet proscribed by Dietary Standards & 0.67 & 1 & 0.79 \\
\hline Avoid drinking alcohol or partying too much & 0.35 & 1 & 0.54 \\
\hline Take Vitamins daily & 0.33 & 1 & 0.85 \\
\hline $\begin{array}{l}\text { Follow advice of people who know more about health than } \\
\text { you }\end{array}$ & 1.43 & 1 & 0.23 \\
\hline Pray and live by religious principles & 0.11 & 1 & 0.73 \\
\hline Avoid areas with high pollution & 2.65 & 1 & 0.1 \\
\hline Take over the counter medicines & 9.98 & 1 & 0.01 \\
\hline Discuss health concerns with family and friends & 0.01 & 1 & 0.97 \\
\hline See doctor when ill and follow their advice & 0.46 & 1 & 0.49 \\
\hline When ill, take prescription medicines suggest by a physician & 0.53 & 1 & 0.46 \\
\hline
\end{tabular}

get them down $\left[\mathrm{X}^{2}(1)=4.34, \mathrm{p}<.03\right]$ and being more likely to take over the counter medications $\left[\mathrm{X}^{2}(1)=9.98, \mathrm{p}<.01\right]$.

Bivariate associations between prior substance abuse treatment participation (e.g., yes versus never) and correlates of individual selfefficacy items as well as corresponding prevalence ratios and their $95 \%$ confidence intervals are presented in Table 3 . In addition, Table 3 also serves a descriptive purpose by showing the proportions of those who reported having participated in substance abuse treatment previously, and those that did not with respect to their agreement or disagreement with selected correlates.

With respect to computed odds ratios, African American male inmates with a past history of participating and/or receive some form of substance abuse treatment were more than 2.5 times more likely to report being more likely to use health protective information (OR $=2.46,95 \% \mathrm{CI}=0.94-6.42)$ and nearly three times more likely to indicate that they would adhere to a diet ascribed by dietary standards $(\mathrm{OR}=2.79,95 \% \mathrm{CI}=1.13-6.91)$ upon release from prison. It was also noted that study respondents were almost two and a half times more likely to indicate they would avoid drinking and partying too much upon release from prison if they had been part of a substance use treatment program prior $(\mathrm{OR}=2.41,95 \% \mathrm{CI}=1.04-5.87)$.

Other health efficacious practices African American male inmates with a past history of participation in substance abuse treatment exhibited being more likely to carry out upon release from prison included doing things in moderation $(\mathrm{OR}=2.46,95 \% \mathrm{CI}=0.94-$ 6.42), avoid over working ( $\mathrm{OR}=2.22,95 \% \mathrm{CI}=0.94-5.23)$, limiting foods containing fats and sugars $(\mathrm{OR}=2.79,95 \% \mathrm{CI}=1.12-6.91)$ and seeing a doctor for regular check-ups $(\mathrm{OR}=1.81,95 \% \mathrm{CI}=0.78$ 4.19).

\section{Discussion}

The goal of this investigation was to examine a potential distal role for self-reported health self-efficacy being enhanced among a sample of African American male inmates based on prior participation in a substance abuse/use treatment program. Our findings did document differences in the likelihood of offender's health self-efficacious behaviors as a function of prior history of substance use treatment. What is of more significance is that offenders in general, regardless of treatment history with higher levels of self-efficacy demonstrated more self-interest in individual beneficial health practices.

We began this research on the basis of our analysis of the literature that there had been little examination of any role for alcohol use in risky sex other than at the time of sexual activity. Our findings join others that have document that self-efficacy can be a positive factor in health behavior change and maintenance [47-49]. The observation that in terms of basic self-control efficacy, offenders with higher health self-efficacy with past treatment indicated doing things in moderation avoiding over working and limiting the consumption of foods that contained fats and sugars.

Though our hypotheses regarding a distal role for health selfefficacy being greater in offenders with a prior history of substance use were not borne out across the board, for many of the individual health self-efficacy items in other ways our results were quite encouraging. We supported the validity of the premise that consistent with social cognitive theory, documenting that health self-efficacy is predictive of certain health of behaviors, similar to the role of health self-efficacy on the use of health information observed by other researchers [50].

An unexpected finding was the level of high self-efficacy among offenders regardless of indicating if they had received treatment for drug abuse in the past. This may indicate the possibility of a protective benefit to individual offenders believing their own action can aid in the development of healthy life styles. This also serves to highlight the difficulty of solidifying the relationship between drug abuse treatment successes with indices of overall health self-efficacy. However this is also problematic given the specific fact all observations are based on a sample of African American male offender, with specific regional attributes, there for it is not possible to preclude confidently causal conclusions from this study.

An alternative explanation for study observations may suggest that low self-efficacy levels may be related to other mental issues such as depression [51], since many offenders with substance abuse issues frequently display comorbidity associated with metal health problems [52]. However, we did not measure these psychological factors, to be consistent of such an assertion, we would have to evaluate such and this study did not collect such data. But it might be presumed 
Table 3: Results of ordinal logistic regression for higher health self-efficacy with respect to prior substance use Treatment $(n=29)$ and No Treatment $(n=96)$

\begin{tabular}{|c|c|c|c|}
\hline After being released from prison & $\%$ & OR & $\mathrm{Cl}$ \\
\hline Eat Sensibly & & 0.58 & $.15-2.16$ \\
\hline Treatment & 89.7 & & \\
\hline No Treatment & 83.5 & & \\
\hline Get Enough Exercise & & 1.43 & $.60-3.41$ \\
\hline Treatment & 62.1 & & \\
\hline No Treatment & 70.1 & & \\
\hline Get Enough Sleep & & 0.54 & $.17-1.73$ \\
\hline Treatment & 86.2 & & \\
\hline No Treatment & 77.3 & & \\
\hline Get Enough Relaxation & & 0.58 & $.22-1.58$ \\
\hline Treatment & 79.3 & & \\
\hline No Treatment & 69.1 & & \\
\hline Watch Your Weight & & 0.47 & $.18-1.21$ \\
\hline Treatment & 79.9 & & \\
\hline No Treatment & 59.8 & & \\
\hline Not Smoke Cigarettes & & 1.03 & $.44-2.41$ \\
\hline Treatment & 41.4 & & \\
\hline No Treatment & 42.3 & & \\
\hline See a Doctor For Regular Check Up & & 1.81 & $.78-4.19$ \\
\hline Treatment & 51.7 & & \\
\hline No Treatment & 66 & & \\
\hline Do things in moderation & & 2.46 & $.94-6.42$ \\
\hline Treatment & 69 & & \\
\hline No Treatment & 84.5 & & \\
\hline Avoid Over Working & & 2.22 & $.94-5.23$ \\
\hline Treatment & 55.2 & & \\
\hline No Treatment & 73.2 & & \\
\hline Limit Foods containing Fats and Sugars & & 2.79 & $.1 .12-6.91$ \\
\hline Treatment & 27.6 & & \\
\hline No Treatment & 51.5 & & \\
\hline Not Let Thing Get You Down & & 2.47 & $1.04-5.87$ \\
\hline Treatment & 55.2 & & \\
\hline No Treatment & 75.3 & & \\
\hline Take Weekly Saunas & & 0.58 & $.21-1.58$ \\
\hline Treatment & 79.3 & & \\
\hline No Treatment & 69.1 & & \\
\hline $\begin{array}{l}\text { Prevent Illness by Following suggestions of local } \\
\text { pharmacist }\end{array}$ & & 0.47 & $.18-1.21$ \\
\hline Treatment & 75.9 & & \\
\hline No Treatment & 59.8 & & \\
\hline $\begin{array}{l}\text { Keep Cold Remedies and Aspirin around the } \\
\text { House }\end{array}$ & & 1.04 & $.44-2.47$ \\
\hline Treatment & 41.4 & & \\
\hline No Treatment & 42.3 & & \\
\hline $\begin{array}{l}\text { Use Health Protective Information provided by a } \\
\text { Health Columnist }\end{array}$ & & 2.46 & $.94-6.42$ \\
\hline
\end{tabular}

\begin{tabular}{|c|c|c|c|}
\hline Treatment & 69 & & \\
\hline No Treatment & 84.5 & & \\
\hline Avoid getting chilled & & 2.22 & $.94-5.23$ \\
\hline Treatment & 55.2 & & \\
\hline No Treatment & 73.2 & & \\
\hline Adhere to diet proscribed by Dietary Standards & & 2.79 & $1.13-6.91$ \\
\hline Treatment & 27.6 & & \\
\hline No Treatment & 51.5 & & \\
\hline Avoid drinking alcohol or partying too much & & 2.41 & $1.04-5.87$ \\
\hline Treatment & 55.2 & & \\
\hline No Treatment & 75.3 & & \\
\hline Take Vitamins daily & & 1.17 & $.46-2.93$ \\
\hline Treatment & 27.6 & & \\
\hline No Treatment & 30.9 & & \\
\hline $\begin{array}{l}\text { Follow advice of people who know more about } \\
\text { health than you }\end{array}$ & & 1.24 & $.52-2.93$ \\
\hline Treatment & 62.1 & & \\
\hline No Treatment & 67 & & \\
\hline Pray and live by religious principles & & 0.98 & $.32-2.93$ \\
\hline Treatment & 82.8 & & \\
\hline No Treatment & 82.5 & & \\
\hline Avoid areas with high pollution & & 1.03 & $.44-2.44$ \\
\hline Treatment & 62.1 & & \\
\hline No Treatment & 62.9 & & \\
\hline Take over the counter medicines & & 1.47 & $.47-4.62$ \\
\hline Treatment & 82.8 & & \\
\hline No Treatment & 87.6 & & \\
\hline Discuss health concerns with family and friends & & 1.12 & $.47-2.67$ \\
\hline Treatment & 34.5 & & \\
\hline No Treatment & 37.1 & & \\
\hline See doctor when ill and follow their advice & & 1.3 & $.54-3.08$ \\
\hline Treatment & 62.1 & & \\
\hline No Treatment & 68 & & \\
\hline $\begin{array}{l}\text { When ill, take prescription medicines suggest by } \\
\text { a physician }\end{array}$ & & 1.08 & $.45-2.55$ \\
\hline Treatment & 62.1 & & \\
\hline No Treatment & 63.9 & & \\
\hline
\end{tabular}

that these psychological occurrences would be more present in drug abusers without a past history of treatment with low Health SelfEfficacy when compared to offenders with High Health self-efficacy with past treatment experience. This is an indication considerable more research is conducted examining health self-efficacy in offender populations in concert with other physical or mental health problems they may express.

Objectively speaking, these null results are disappointing from the perspective of gaining a basic understanding of the exact role of health self-efficacy, if any in treatment adherences and the reduction of subsequent STI risk practices. On the other hand, these results are somewhat encouraging from the perspective of intervention 
development. They suggest that intervention content based on the assumption that attitudes affiliated with self-efficacy are related to overall improved health self-awareness and may be beneficial in both enhancing results from treatment participation as well as provide extended benefits that serve to reduce other health outcomes associated with reformed drug abuse behavior. This has been pointed out by investigators in other areas that proffer the utility of efficacybased interventions [53-55].

Although our findings are unique and add to the current corpus of research, this study is not without limitations. One is that our conclusions are based on self-reporting of future practices by an incarcerated population and thus we suggest caution in the interpretation of our findings. Also, the reliance on a methodology that involves the collection of survey data may engender concerns pertaining to the reliability of self-reported outcome measures (i.e., health self-efficacy, past drug abuse treatment) may bring about concerns pertaining to reliability of or findings and results. Although a multitude of studies have supported validity and reliability of selfreport measures none examined adult male offenders whom were African Americans [55,56].

Another limitation our dependence on subjective health index such as health self-efficacy. Future studies need to include measures of both objective and subjective health self-efficacy in addition to more comprehensive measures of specific attributes affiliated with drug abuse treatment delivery such as required hours of participation should be considered. Finally, there are some concerns about the nature of the sample. The present sample is fairly representative of the population of offenders in the state of Georgia. However, its selective nature does not reflect the racial and ethnic diversity of the U.S. population. Future studies should therefore aim to recruit more diverse samples with particular emphasis on the inclusion of racial/ ethnic minorities as well as age-based factors in different regions of the country. Inspite of these limitations, the present study makes important contributions to the scarce literature on personality-health links among how offenders with past history of drug abuse treatment the mediating role of caregiver strain and multi-domain self-efficacy.

\section{Conclusion}

In the United States today, 1 in 33 Americans is incarcerated at some point, and high rates of recidivism, substance use practices, and overall risk taking and the transient nature of this population make correctional health truly a community issue. Moreover, offenders are reflections of marginalized communities and as such, in particular respect to African Americans, correctional populations represent a large and vulnerable segment of the population that often exhibit poor substance abuse treatment outcomes.

What is clear from the present study is that evidence supports the existence of an essential role of health self-efficacy when attempting to engender improved health behaviours that can both reduce substance abuse and risk for the spread and contracting of STIs. Our sample of African American adult male inmates in Georgia as a function of past self-reported history of having received treatment for a drug problem prior incarceration has provided information that will add to our understanding of self-efficacy as a construct in several ways. First, the construct of perceived health self-efficacy represents one central proponent of social-cognitive theory and refers to personal control of actions or agency. Agency and action are essential in any treatment related behavior especially related to substance abuse. Second, according to our results, these factors might be strongly associated with the time to terms of reciprocity between self-efficacy and health, evidence from longitudinal studies suggested that selfefficacy determines health-related outcomes, but changes in diagnosis do not predict changes in self-efficacy.

This study has clinical relevance in the development of substance use treatment and patient education materials on STI risk reduction for offender populations. In particular because of since the correctional setting presents an opportunity to access a significant subset of this population and provide ethical, evidencebased interventions. Such knowledge might be helpful to improve the effectiveness of treatment, because efficacy associated with treatment adherences may possibly serve to reduce risk taking in other areas, when treatment is effective, in particular knowing that correctional setting presents an opportunity to access a significant subset of this population and provide ethical, evidence-based interventions. Especially interventions that merge substance use and STI risk reduction efforts with offender populations that aim to enhance selfmanagement in the manner in which it has been shown with other health related problem control issues in which Self-efficacy was independently associated with improving health behaviors.

\section{Funding}

This Research was funded by the National Institute on Drug Abuse [1 R01 DA122331-01A1].

\section{References}

1. Sabol WJ \& Minton TD. Jail inmates at midyear 2007. Bureau of Justice Statistics, US Department of Justice. NCJ. 2008; 221945.

2. Broad J, Cox T, Rodriguez S, Mansour M, Mennella C, Murphy-Swallow D, et al. The impact of discontinuation of male STD screening services at a large urban county jail: Chicago, 2002-2004. Sexually transmitted diseases. 2009; 36: S49-S52.

3. Johnson DF, Sorvillo FJ, Wohl AR, Bunch G, Harawa NT, Carruth A, et al. Frequent failed early HIV detection in a high prevalence area: implications for prevention. AIDS Patient Care and STDs. 2003; 17: 277-282.

4. Pathela P, Hennessy RR, Blank S, Parvez F, Franklin W, Schillinger JA. The contribution of a urine-based jail screening program to citywide male Chlamydia and gonorrhea case rates in New York City. Sexually transmitted diseases. 2009; 36: S58-S61.

5. George WH \& Stoner SA. Understanding acute alcohol effects on sexual behavior. Annual review of sex research. 2000; 11: 92-124.

6. Cooper ML. Alcohol use and risky sexual behavior among college students and youth: evaluating the evidence. Journal of Studies on Alcohol, supplement. 2002; 101-117.

7. Stephens $T$, Sifunda S, Braithwaite R, \& Reddy P. Prospective Examination of Marital Status as a Determinant of Sexual Risk Taking Behavior among Inmates in KwaZulu-Natal and Mpumalanga Provinces, South Africa. Journal of Behavioral Health. 2016; 5: 7-11.

8. Stephens TT, Ogbuawa N \& Braithwaite R. Demographic profile of inhalant, amphetamine, ecstasy, and heroin use among prerelease male inmates in Georgia. The journal of men's health \& gender. 2007; $4: 74-80$.

9. Stephens TT, Gardner D, Jones K, Sifunda S, Braithwaite R, \& Smith SE. Correlates of mandrax use and condom beliefs in preventing sexually transmitted infections among a cohort of South African Prison inmates. International health. 2016; 8: 142-147. 
10. Testa M, Fillmore MT, Norris J, Abbey A, Curtin JJ, Leonard KE, et al Understanding alcohol expectancy effects: Revisiting the placebo condition. Alcoholism: Clinical and Experimental Research. 2006; 30: 339-348.

11. Testa M. The impact of men's alcohol consumption on perpetration of sexual aggression. Clinical psychology review. 2002; 22: 1239-1263.

12. Stephens T, Braithwaite R, \& Conerly R. Self-reported injection drug use and needle sharing behavior among soon-to-be-released adult male inmates. American Journal of Health Studies. 2005; 20: 66.

13. Glaze LE, \& Kaeble D. Correctional populations in the United States, 2013 (NCJ 248479). US Department of Justice. 2014

14. Minton TD \& Zeng Z. Jail inmates at midyear 2014. NCJ, 241264. 2015.

15. Carson EA. Prisoners in 2014 (NCJ 248955). Retrieved from Bureau of Justice Statistics. 2015.

16. Fazel S, Bains $P$ \& Doll H. Substance abuse and dependence in prisoners: a systematic review. Addiction. 2006; 101: 181-191.

17. Spaulding AC, Seals RM, Page MJ, Brzozowski AK, Rhodes W, Hammett TM HIVIAIDS among inmates of and releasees from US correctional facilities, 2006: declining share of epidemic but persistent public health opportunity. PloS one. 2009; 4: e7558.

18. Barskey AE, SurenderaBabu A, Hernandez A, Espinoza L. Patterns and Trends of Newly Diagnosed HIV Infections Among Adults and Adolescents in Correctional and Noncorrectional Facilities, United States, 2008-2011. American journal of public health. 2016; 106: 103-109.

19. Okie S. Sex, drugs, prisons, and HIV. New England Journal of Medicine. 2007; 356: 105-108.

20. Small W, Kain S, Laliberte N, Schechter MT, O'shaughnessy MV, Spittal PM Incarceration, addiction and harm reduction: inmates experience injecting drugs in prison. Substance use \& misuse. 2005; 40: 831-843.

21. Goddard P. Changing attitudes towards harm reduction among treatment professionals: A report from the American Midwest. International Journal of Drug Policy. 2003; 14: 257-260.

22. Bandura A. Self-efficacy: toward a unifying theory of behavioral change Psychological review. 1977; 84: 191.

23. Sarkar U, Fisher L, Schillinger D. Is self-efficacy associated with diabetes self-management across race/ethnicity and health literacy? Diabetes care. 2006; 29: 823-829.

24. Becker H, Stuifbergen A, Oh HS, Hall S. Self-rated abilities for health practices: A health self-efficacy measure. Health Values: The Journal of Health Behavior, Education \& Promotion. 1993.

25. O'Leary A. Self-efficacy and health. Behaviour research and therapy. 1985; 23: $437-451$

26. Schwarzer R, Renner B. Social-cognitive predictors of health behavior: action self-efficacy and coping self-efficacy. Health psychology. 2000; 19: 487

27. Jackson ES, Tucker CM, Herman KC. Health value, perceived social support, and health self-efficacy as factors in a health-promoting lifestyle. Journal of American College Health. 2007; 56: 69-74

28. Sheeran P, Maki A, Montanaro E, Avishai-Yitshak A, Bryan A, Klein WM, et al. The impact of changing attitudes, norms, and self-efficacy on healthrelated intentions and behavior: A meta-analysis. 2016; 35: 1178-1188.

29. Strecher VJ, McEvoy DeVellis B, Becker MH, Rosenstock IM. The role of self-efficacy in achieving health behavior change. Health education quarterly. 1986; 13: 73-92.

30. Marks R, Allegrante JP. A review and synthesis of research evidence for selfefficacy-enhancing interventions for reducing chronic disability: implications for health education practice (part II). Health promotion practice. 2005; 6 : 148-156

31. Lee SY, Hwang H, Hawkins R, Pingree S. Interplay of negative emotion and health self-efficacy on the use of health information and its outcomes. Communication Research. 2008; 35: 358-381.
32. Bandura A. Social foundations of thought and action: A social cognitive theory. NY: Prentice-Hall. 1986.

33. Bandura A. Self-efficacy: The exercise of control. Macmillan. 1997

34. Lorig KR, Holman HR. Self-management education: history, definition, outcomes, and mechanisms. Annals of behavioral medicine. 2003; 26: 1-7.

35. Aljasem LI, Peyrot M, Wissow L, Rubin RR. The impact of barriers and selfefficacy on self-care behaviors in type 2 diabetes. The Diabetes Educator. $2001 ; 27: 393-404$

36. Bernal H, Woolley S, Schensul JJ, Dickinson JK. Correlates of self-efficacy in diabetes self-care among Hispanic adults with diabetes. The Diabetes Educator. 2000; 26: 673-680.

37. Hurley AC, Shea CA. Self-efficacy: strategy for enhancing diabetes self-care. The Diabetes Educator. 1992; 18: 146-150.

38. Loeb SJ, Steffensmeier D. Older male prisoners: Health status, self-efficacy beliefs, and health-promoting behaviors. Journal of Correctional Health Care. 2006; 12: 269-278.

39. Skogstad P, Deane FP, Spicer J. Social-cognitive determinants of helpseeking for mental health problems among prison inmates. Criminal Behaviour and Mental Health. 2006; 16: 43-59.

40. Stephens TT, Braithwaite R, Conerly R, Brantley K. Predictors of condom use among a sample of male inmates: a social cognitive perspective. Journal of the National Medical Association. 2006; 98: 574.

41. Dolan SL, Martin RA, Rohsenow DJ. Self-efficacy for cocaine abstinence: Pretreatment correlates and relationship to outcomes. Addictive behaviors. 2008; 33: 675-688.

42. Maisto SA, Connors GJ, Zywiak WH. Alcohol treatment changes in coping skills, self-efficacy, and levels of alcohol use and related problems 1 year following treatment initiation. Psychology of Addictive Behaviors. 2000; 14 : 257.

43. McKay JR, Foltz C, Leahy P, Stephens R, Orwin RG, Crowley EM. Step down continuing care in the treatment of substance abuse: Correlates of participation and outcome effects. Evaluation and Program Planning. 2004 27: 321-331.

44. Seyde E, Taal E, Wiegman O. Risk-appraisal, outcome and self-efficacy expectancies: Cognitive factors in preventive behaviour related to cancer. Psychology and Health. 1990; 4: 99-109.

45. Cleveland WS, Devlin SJ. Locally weighted regression: an approach to regression analysis by local fitting. Journal of the American statistical association. 1988; 83: 596-610.

46. Azzalini A, Capitanio A. Statistical applications of the multivariate skew normal distribution. Journal of the Royal Statistical Society: Series B (Statistical Methodology). 1999; 61: 579-602.

47. Beck KH, Lund AK. The Effects of Health Threat Seriousness and Personal Efficacy upon Intentions and Behavior1. Journal of Applied Social Psychology. 1981; 11: 401-415.

48. Sitharthan T, Kavanagh DJ. Role of self-efficacy in predicting outcomes from a programme for controlled drinking. Drug and alcohol dependence. 1991; 27: 87-94.

49. von Wagner C, Semmler C, Good A, Wardle J. Health literacy and selfefficacy for participating in colorectal cancer screening: the role of information processing. Patient education and counseling. 2009; 75: 352-357.

50. Arnstein P, Caudill M, Mandle CL, Norris A, Beasley R. Self efficacy as a mediator of the relationship between pain intensity, disability and depression in chronic pain patients. Pain. 1999; 80: 483-491.

51. Bandura A. Self-efficacy mechanism in human agency. American psychologist. 1982; 37: 122

52. McAuley E, Blissmer B. Self-efficacy determinants and consequences of physical activity. Exercise and sport sciences reviews. 2000; 28: 85-88.

53. King TK, Marcus BH, Pinto BM, Emmons KM, Abrams DB. Cognitive- 
behavioral mediators of changing multiple behaviors: smoking and a sedentary lifestyle. Preventive medicine. 1996; 25: 684-691.

54. King DK, Glasgow RE, Toobert DJ, Strycker LA, Estabrooks PA, Osuna D, et al. Self-efficacy, problem solving, and social-environmental support are associated with diabetes self-management behaviors. Diabetes care. 2010; 33: $751-753$
55. Ochs EP, Binik YM. The use of couple data to determine the reliability of self-reported sexual behavior. Journal of Sex Research. 1999; 36: 374-384.

56. Jaccard J, Wan CK. A paradigm for studying the accuracy of self-reports of risk behavior relevant to AIDS: empirical perspectives on stability, recall bias, and transitory influences. Journal of Applied Social Psychology. 1995; 25: 1831-1858
J Fam Med - Volume 4 Issue 3 - 2017

ISSN : 2380-0658 | www.austinpublishinggroup.com

Stephens et al. () All rights are reserved
Citation: Stephens S, Holmes T-K and Allen A. Health Self Efficacy and African American Male Inmates Prior Substance Use Treatment History: Implications for STI Risk Reduction. J Fam Med. 2017; 4(3): 1114 